\title{
Phase I Trial of Sorafenib Following Liver Transplantation in Patients with High-Risk Hepatocellular Carcinoma
}

\author{
Abby B. Siegel a Anthony B. El-Khoueiry ${ }^{b}$ Richard S. Finn ${ }^{c}$ \\ Katherine A. Guthrie ${ }^{d}$ Abhishek Goyal a Alan P. Venook ${ }^{\mathrm{e}}$ \\ Charles D. Blanke $^{f} \quad$ Elizabeth C. Verna ${ }^{a}$ Lorna Dove ${ }^{a}$ \\ Jean Emond ${ }^{a}$ Tomoaki Kato ${ }^{a}$ Benjamin Samstein ${ }^{a}$ \\ Ronald Busuttil c Helen Remotti 9 Amy Coffey ${ }^{9}$ \\ Robert S. Brown Jr a \\ a Columbia University Medical Center Departments of Medicine and Surgery, New York, N.Y., b Norris \\ Comprehensive Cancer Center, Los Angeles, Calif., ' Geffen School of Medicine, Los Angeles, Calif., \\ d Fred Hutchinson Cancer Research Center, Seattle, Wash., e Helen Diller Family Comprehensive \\ Cancer Center, San Francisco, Calif., ${ }^{f}$ Knight Cancer Institute, Portland, Oreg., 9 Division of Pathology \\ and Cell Biology, Columbia University, New York, N.Y., USA
}

\section{Key Words}

Hepatocellular carcinoma · High risk · Liver transplant · Phase I · Sorafenib

\begin{abstract}
Liver transplantation offers excellent long-term survival for hepatocellular carcinoma (HCC) patients who fall within established criteria. For those outside such criteria, or with high-risk pathologic features in the explant, HCC recurrence rates are higher. We conducted a multicenter phase I trial of sorafenib in liver transplantation patients with high-risk HCC. Subjects had HCC outside the Milan criteria (pre- or post-transplant), poorly differentiated tumors, or vascular invasion. We used a standard $3+3$ phase I design with a planned duration of treatment of 24 weeks. Correlative studies included the number of circulating endothelial cells (CECs), plasma biomarkers, and tumor expression of p-Erk, p-Akt, and c-Met in tissue microarrays. We enrolled 14 patients with a median age of 63 years. Of these, 93\% were men and $71 \%$ had underlying hepatitis $\mathrm{C}$ virus (HCV) and $21 \%$ had HBV. The maximum tolerated dose of sorafenib was $200 \mathrm{mg}$ BID. Grade 3-4 toxicities seen in $>10 \%$ of subjects included leuko-
\end{abstract}

Presented in part at the Gastrointestinal Cancers Symposium, San Francisco, 2013 and 2015 and at the American Society of Clinical Oncology Meeting, Chicago, 2011. 
penia (21\%), elevated gamma-glutamyl transferase (21\%), hypertension (14\%), hand-foot syndrome (14\%) and diarrhea (14\%). Over a median follow-up of 953 days, one patient died and four recurred. The mean CEC number at baseline was 21 cells/4 ml for those who recurred, and 80 cells $/ 4 \mathrm{ml}$ for those who did not $(p=0.10)$. Mean soluble vascular endothelial growth factor receptor-2 levels decreased after 1 month on sorafenib $(p=0.09)$, but did not correlate with recurrence. There was a trend for tumor c-Met expression to correlate with increased risk of recurrence. Post-transplant sorafenib was found to be feasible and tolerable at $200 \mathrm{mg} P O$ BID. The effect of post-transplant sorafenib on recurrence-free survival is potentially promising but needs further validation in a larger study.

Copyright (c) 2015 S. Karger AG, Basel

\section{Introduction}

Hepatocellular carcinoma (HCC) is the third leading cause of cancer deaths worldwide and accounts for about 13,000 deaths in the United States per year [1]. Liver transplantation offers selected patients with localized HCC a chance for cure. For those meeting the Milan criteria, defined as a single tumor $2-5 \mathrm{~cm}$ or three or fewer nodules, each $3 \mathrm{~cm}$ or less, and no gross vascular invasion, 5 year survival for transplanted patients is about $75 \%$ [2, 3]. Meeting these criteria provides additional priority for transplantation in the US. However, for those with HCC beyond the Milan criteria, whether determined pre-transplant or by pathologic evaluation of the explant, the risk of recurrence may be as high as $70 \%$ at 2 years after transplantation [4]. There are few studies evaluating adjuvant therapy after resection or transplantation for HCC, and there is no standard of care for the treatment of these patients. Finding an effective agent which decreases recurrence rates in high-risk patients would be a significant advance.

Sorafenib (Nexavar; Bayer, West Haven, CT, USA, and Onyx, Emeryville, CA, USA) is an oral multi-kinase inhibitor with effects on tumor proliferation and angiogenesis [5]. It demonstrates inhibitory activity against the serine/threonine kinases Raf- 1 and wild-type B-Raf, which are pivotal components of the Ras/Raf/MEK/ERK signaling pathway. Inhibitory activity has also been shown against the tyrosine kinases for vascular endothelial growth factor (VEGF) receptor, platelet-derived growth factor (PDGF) receptor, Flt-3, and c-Kit. Overexpression of Ras and other members of this signaling pathway has been demonstrated in HCC, as has upregulation of VEGF [6, 7].

The multi-center, randomized, placebo-controlled, phase III trial of sorafenib in advanced HCC (SHARP) showed a significant survival benefit in patients treated with sorafenib compared to best supportive care alone in a Western population [8]. This trial established sorafenib monotherapy as first-line therapy for advanced HCC, and a similar benefit was seen in a trial of sorafenib in an Asian/Pacific population [9]. Sorafenib has subsequently been tested in a randomized trial as an adjuvant following definitive non-transplant therapy of HCC (STORM) but was recently shown not to improve survival [10]. It is not known whether a primarily cytostatic drug will be effective in preventing cancer recurrences in the setting of minimal residual disease achieved by implanting a new liver. In this phase I, multicenter study, we explored the maximum tolerated dose (MTD) and overall safety profile of sorafenib as therapy in liver transplant subjects with high-risk HCC. We hypothesized that an increased number of CECs might be a marker for vascular damage and predict a better response to sorafenib during treatment [11]. Similarly, various pro-angiogenic cytokines have been suggested as predictive and prognostic biomarkers in HCC patients treated with sorafenib $[12,13]$. For this reason, we conducted an exploratory investigation of correla- 
tions between circulating endothelial cells, plasma markers [including VEGF, soluble VEGF receptors (sVEGFR1-3), IL-6, angiopoietin-2, and hepatocyte growth factor (HGF)] and outcome in preparation for a larger, randomized trial of sorafenib in this setting. We also examined expression of potential predictive and prognostic tumor tissue biomarkers, including c-Met, p-Akt, and p-Erk.

\section{Materials and Methods}

\section{Subjects}

Post-liver-transplant HCC patients aged 18 years or older with histologically confirmed HCC on explant were recruited. Subjects were defined as "high risk" for recurrence by being outside the Milan criteria either by radiologic criteria before transplant or pathologic criteria in the explant, by having tumors with vascular invasion, or by having poorly differentiated tumor histology. Eligibility criteria also included ECOG Performance Status 0-2, and adequate bone marrow, liver, and renal function. Patients were required to start treatment within 16 weeks after transplantation. Patients could have received prior surgical resection, chemoembolization, or other locoregional therapy prior to transplant. We also noted whether subjects were within the University of California, San Francisco, (UCSF) criteria pre or post-transplant, defined as a single nodule up to $6.5 \mathrm{~cm}$, or up to three nodules, none larger than $4.5 \mathrm{~cm}$, with the total tumor diameter being no more than $8 \mathrm{~cm}$ [14].

Exclusion criteria included having received prior anti-angiogenic therapy, systemic targeted agents, or chemotherapy, and previous or simultaneous mammalian target of rapamycin (mTOR) inhibitors. Additional exclusion criteria included significant cardiac disease, including myocardial infarction, within the previous 6 months, uncontrolled hypertension, serious bleeding, or a non-healing wound within 4 weeks prior to first dose of study drug. The study was approved by the Columbia University institutional review board (IRB) as well as the IRBs of participating sites, and all subjects provided written informed consent.

\section{Study Design and Treatment}

We used a standard phase I dose-escalation design, with planned dose levels of: (1) 200 mg daily, (2) $200 \mathrm{mg} \mathrm{BID}$, (3) $200 \mathrm{mg} / 400 \mathrm{mg}$, and (4) $400 \mathrm{mg}$ BID. The relatively low starting dose of sorafenib was chosen because of potential interactions between sorafenib and anti-rejection medications such as cyclosporine. Since calcineurin inhibitors inhibit CYP3A4 metabolism, we hypothesized that a significantly lower dose of sorafenib might be necessary in patients being administered such drugs. Immunosuppressant levels were checked weekly for the first 2 months and then every 2 weeks for the next 6 months. Mycophenolate serum levels are not routinely measured in post-transplant patients. With the introduction of sorafenib to the postoperative regimen, serum mycophenolate levels were measured only if there was a concern for organ rejection or unexpected toxicity. Sorafenib compliance was assessed via pill counts at each visit. We did not assess sorafenib levels because of lack of evidence that interpatient variability in sorafenib pharmacokinetics contributes to differences in adverse effects, and because of cost constraints [15]. If toxicities occurred, sorafenib was stopped as the first step if there was any concern that it could be a potential cause. Algorithms for assessing cytopenias and liver function were then implemented together with the transplant team for each patient, including evaluating other medications, ruling out infection, and assessment of liver rejection and cancer recurrence.

Patients were followed for evidence of toxicity with weekly visits for the first 4 weeks after the start of sorafenib administration and then every 2 weeks. Computed tomography scans of the chest and magnetic resonance imaging of the abdomen were performed every 3 months for 2 years per protocol. Serum alpha-fetoprotein (AFP) was measured every 2 weeks for the first 6 months, then every 3 months for atotal of 2 years. Patients maintained routine transplantcare provided by their hepatologist. Recurrenttumors were measured using Response Evaluation Criteria in Solid Tumors criteria, with one radiologist blinded to study participation. An increased AFP relative to enrollment prompted further evaluation with imaging for cancer recurrence. All recurrences were confirmed pathologically.

The maximum tolerated dose (MTD) was defined as the highest dose at which fewer than two patients experienced a dose-limiting toxicity (DLT) of a total of six patients treated at that dose. The NCI Common Terminology Criteria for Adverse Events, Version 3.0, was used. DLT was defined as any one of the following: $\geq$ grade 3 non-hematological toxicity excluding nausea, vomiting, diarrhea, headache, urticaria, rash, hand-foot syndrome, constipation, transaminase elevation, gamma-glutamyl transferase elevation (GGT) (protocol amended August 19, 2011 removing grade 3 GGT as a DLT), asymptomatic hypophospha- 
temia, or asymptomatic lipase elevation that could be controlled with supportive medications. Febrile neutropenia, grade 4 neutropenia, and platelet count $<25,000 / \mathrm{uL}$ were also considered DLTs. We intentionally tried to keep the DLT definition liberal (i.e., excluding some significant toxicities of sorafenib) in order to avoid early study closure. We followed clear dose-reduction and stopping rules in the protocol to ensure subject safety. All enrolled patients were evaluated in an intention-to-treat analysis. Study treatment continued until unacceptable toxicity developed or until the subject or investigator chose to discontinue study treatment. Due to potential increased risk of skin cancers on sorafenib treatment in post-transplant patients, skin examinations every 6 months with a dermatologist were required.

\section{Correlative Studies}

We evaluated circulating endothelial cells (CECs) [CD146 (+), CD45 (-), and CD31 (+) cells] using the Veridex system for a random subset of subjects at three different time points: after transplant and enrollment but prior to sorafenib start, at 28 days after sorafenib start, and at recurrence, if applicable. Samples were processed according to manufacturer's instructions to assess correlations with sorafenib treatment and time to progression in an exploratory analysis. Initial samples were analyzed at Columbia, but later samples were sent to Veridex due to personnel and equipment changes. All CEC samples were ultimately re-analyzed at Veridex Clinical Laboratories in Huntingdon Valley, PA, USA, for consistency. We also planned to draw plasma from the same random subset of subjects to be frozen and batched for evaluation of potential plasma prognostic biomarkers including VEGF, sVEGFR1, sVEGFR2, and HGF [all enzyme-linked immunosorbent assays (ELISAs) by R\&D], sVEGFR3 (Biovendor ELISA), IL-6, angiopoietin-2 (Abcam ELISA) at the same time points as described above. All assays were run in duplicate by the Herbert Irving Clinical Research Biomarker Core.

A tissue microarray (TMA) block was then constructed from representative paraffin-embedded blocks from the 13 explanted liver specimens with HCC seen at Columbia. The construction of the TMA was conducted using a tissue arrayer (Beecher Instruments, Sun Prarie, WI). Each tumor specimen was represented by two 1.5-mm tumor cores and one non-tumor core in the TMA block. For each case, at least one tumor, including the highest-grade tumor, was selected for the TMA (1-4 tumors per patient) and non-lesional liver tissue from the same specimens was used as control. The TMA block was cut in 4- $\mu \mathrm{m}$ sections and immunolabeled with antibodies directed against the following rabbit monoclonal antibodies: c-MET (SP44), prediluted, CONFIRM (Ventana, Tucson, AZ); phospho-ERK1/2 [phospho p44/42 Map kinase (Erk1/2) (Thr202 / Tyr204) (D13.14.4E), 1:300 dilution, Cell Signaling Technology, Danvers, MA]; and phospho-Akt (Ser 473) (736E11), 1:40 dilution, Cell Signaling Technology.

Immunostaining for c-Met was carried out using an automated immunohistochemical stainer according to the manufacturer's guidelines (streptavidin-peroxidase with automated Ventana Benchmark, Ventana). Immunostaining for phospho-ERK1/2 and phospho-Akt were processed manually. Slides were deparaffinized and submitted to antigen retrieval by microwave treatment for $20 \mathrm{~min}$ in $10 \mathrm{mM}$ citrate buffer, followed by primary antibody incubation for $90 \mathrm{~min}$ at room temperature. Then slides were incubated with biotinylated anti-rabbit immunoglobulin (Vector Laboratories, Burlingame, CA) at a 1:200 dilution for $30 \mathrm{~min}$ followed by avidin-biotin peroxidase complexes (Vector Laboratories) at a 1:50 dilution for $30 \mathrm{~min}$. Diaminobenzidine was used as the chromogen and hematoxylin as a nuclear counterstain. Substitution of the primary antibody with phosphate-buffered saline was used as a negative control.

\section{Staining Evaluation}

Immunostaining was evaluated independently by two pathologists (HR, AC) using the following criteria: p-Akt, p-Erk, and c-Met were assessed by intensity of staining (negative, 0; weak, 1; moderate, 2; and strong, 3 ) and by the percentage of stained cells. The pattern of expression (cytoplasmic, membranous, and nuclear) was noted. Expression for p-Akt and p-Erk was defined as positive when the intensity of staining was $2+$ or higher and the percentage of cells stained was greater than $1 \%$. For c-Met expression, samples that scored at least $2+$ in at least $50 \%$ of tumor cells were regarded as having high c-Met expression (c-Met-high), using a scoring system previously reported [16].

\section{Statistical Analysis}

Summary statistics were used to describe subject characteristics and clinical variables. Independent group $t$-tests were used to compare baseline biomarker levels between the groups of patients who recurred and those who did not. Paired $t$-tests were used to compare baseline biomarker levels with levels after 1 month on sorafenib. Log-rank tests were used to compare recurrence rate by immunostain results. Recurrence-free survival estimates were calculated using the Kaplan-Meier method. Subjects contributed person-time from the treatment start date to the date of recurrence/date of censoring (i.e., the end of study period: December 1, 2013). No study participant was lost to follow-up during the study 

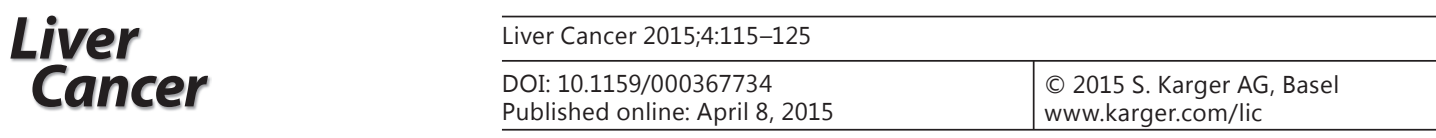

period. $\mathrm{p}<0.05$ was considered statistically significant. All analyses were performed using SAS, version 9.3.

\section{Results}

We enrolled 14 patients with a median age of 63 years; 93\% were men. Underlying HCV was found in $71 \%$ of subjects, while $21 \%$ had underlying HBV; $21 \%$ had significant underlying alcohol use. A total of $93 \%$ had an ECOG performance status of 1 on enrollment, and ChildPugh scores pre-transplant were 43\% A, 50\% B, and 7\% C. In addition, 57\% were within the Milan criteria on preoperative imaging. On explant, $29 \%$ had poorly-differentiated tumors, and $36 \%$ had vascular invasion (table 1 ). Six patients received sorafenib at $200 \mathrm{mg}$ per day, three received $200 \mathrm{mg}$ BID, and four ultimately received $200 \mathrm{mg} / 400 \mathrm{mg}$ per day. MTD was $200 \mathrm{mg}$ BID, and only $43 \%$ of patients received $>80 \%$ of the planned dose overall. Relative dose intensity was calculated and is shown in table 4. DLTs included elevated GGT (1), elevated bilirubin in the setting of transplant rejection leading to death (1), and grade 3 hypertension (1). Grade 3-4 toxicities seen in $>10 \%$ of subjects included: leukopenia (21\%), elevated GGT (21\%), hypertension (14\%), hand-foot syndrome (14\%) and diarrhea (14\%) (table 2). No skin cancers were detected over the follow-up period. Over a median follow-up of 953 days, one patient died and four (29\%) recurred, with a median recurrence-free survival of 716 days for the four patients who recurred $(950,1021,481$, and 135 days respectively) (fig. 1). Of those who recurred, one had a poorly-differentiated tumor and was outside the Milan criteria pre-transplant with a $6 \mathrm{~cm}$ lesion. The second and third who recurred had vascular invasion and were outside the Milan criteria on explant. The fourth patient who recurred was outside Milan pre- and post-transplant, had vascular invasion, and also had high-grade disease.

Peripheral biomarker correlates are shown in table 3 and Supplementary table 1 (for all online suppl. material, see www.karger.com/doi/10.1159/000367734). The mean CEC number at baseline was 21 cells $/ 4 \mathrm{ml}$ for those who recurred and 80 cells $/ 4 \mathrm{ml}$ for those who did not ( $\mathrm{p}=0.10)$. For CEC levels, 11 subjects had baseline and 1 -month values, with a p-value using a paired $t$-test of 0.46 . We have CEC values for only two patients of those who recurred, so these values were not compared with other levels due to small sample sizes. Mean sVEGFR2 levels tended to decrease after 1 month on sorafenib $(\mathrm{p}=0.09)$, but did not predict recurrence.

Biomarker analysis was performed on HCCs sampled in the TMA representing 12 liver explants and 1 adrenal metastasis from 13 patients in this study (Supplementary table 2). Immunostaining for c-Met, p-Erk, and p-Akt was performed on HCCs represented in the TMA. In two patients, pre-transplant liver core needle biopsies were also performed and assessed for p-Erk and p-Akt immunoreactivity. In all HCC tumors sampled in the TMA, neoplastic liver cells were negative for p-Erk expression. In 2 of 12 explants, cytoplasmic and focal nuclear p-Akt immunoreactivity were present (in grade 2 and grade 4 HCC specimens). In the one metastasis evaluated, strong diffuse p-Akt immunoreactivity was noted. In the two pre-transplant core biopsies (case 9 and case 12, both grade 2 HCCs), p-Erk was negative in the tumors, whereas p-Akt was positive in both tumors. The corresponding explants were negative for both p-Erk and p-Akt. None of the stains predicted tumor recurrence. There was a suggestion that tumors that recurred were more likely to have high c-Met expression: two of the four that recurred (50\%), compared with two of the nine that did not recur $(22 \%$; $\mathrm{p}=0.53)$. 
Table 1. Baseline subject characteristics

\begin{tabular}{|c|c|}
\hline Variable & $\mathrm{n}=14$ \\
\hline Age (years) & $62.1(48-74)$ \\
\hline \multicolumn{2}{|l|}{ Sex } \\
\hline Male & $13(93)$ \\
\hline Female & $1(7)$ \\
\hline \multicolumn{2}{|l|}{ Etiologya } \\
\hline HBV & $3(21)$ \\
\hline $\mathrm{HCV}$ & $10(71)$ \\
\hline ЕTOH & $3(21)$ \\
\hline Diabetes mellitus & $1(7)$ \\
\hline \multicolumn{2}{|l|}{ ECOG Performance Status } \\
\hline 0 & $1(7)$ \\
\hline 1 & $13(93)$ \\
\hline \multicolumn{2}{|l|}{ Total tumors } \\
\hline Pre-transplant & $3.0(1-9)$ \\
\hline Post-transplant & $3.4(1-9)$ \\
\hline \multicolumn{2}{|c|}{ Milan Criteria (pre-operative) } \\
\hline Yes & $8(57)$ \\
\hline No & $6(43)$ \\
\hline \multicolumn{2}{|l|}{ UCSF (pre-operative) } \\
\hline Yes & $11(79)$ \\
\hline No & $3(21)$ \\
\hline \multicolumn{2}{|c|}{ Milan Criteria (post-operative) } \\
\hline Yes & $4(29)$ \\
\hline No & $10(71)$ \\
\hline \multicolumn{2}{|l|}{ UCSF (post-operative) } \\
\hline Yes & $8(57)$ \\
\hline No & $6(43)$ \\
\hline \multicolumn{2}{|l|}{ Vascular invasion } \\
\hline Yes & $5(36)$ \\
\hline No & $9(64)$ \\
\hline
\end{tabular}

\section{Discussion}

Liver transplantation offers cure for many HCC patients within the Milan criteria. However, for those outside these criteria, or with aggressive pathologic features such as vascular invasion or high-grade disease, recurrences are more common. No therapy has so far been proven to decrease recurrence in the post-transplant setting. Since sorafenib is the only drug known to improve survival in the advanced disease setting, we conducted a phase I trial to assess its safety in a high-risk post-transplant population. Retrospective data in this setting suggested a possible benefit to sorafenib given to eight patients, compared to untreated controls, with the majority of patients tolerating $200 \mathrm{mg}$ BID [17]. A prospective experience of four patients also showed significant toxicity at initial dosing [18]. In a study of sorafenib given to 12 Korean patients with HCC who recurred after transplant, no significant interactions requiring dose adjustments of immunosuppressants were seen [19]. 


\section{Liver \\ Cancer}

\begin{tabular}{|c|c|}
\hline \multicolumn{2}{|l|}{ Liver Cancer 2015;4:115-125 } \\
\hline $\begin{array}{l}\text { DOI: } 10.1159 / 000367734 \\
\text { Published online: April 8, } 2015\end{array}$ & $\begin{array}{l}\text { (c) } 2015 \text { S. Karger AG, Basel } \\
\text { www.karger.com/lic }\end{array}$ \\
\hline
\end{tabular}

Table 2. Incidence of drug-related toxicities (grades 3 and 4)

\begin{tabular}{lll}
\hline Toxicity & Grade 3 (\%) & Grade 4 (\%) \\
$\begin{array}{ll}\text { Liver dysfunction } \\
\text { Total bilirubin }\end{array}$ & $1(7)$ & $1(7)$ \\
ALP & $1(7)$ & \\
ALT & $1(7)$ & \\
AST & $1(7)$ & \\
Hematological & & \\
$\quad$ Leukopenia & $3(21)$ & $1(7)$ \\
$\quad$ Lymphopenia & $3(21)$ & \\
$\quad$ Neutropenia & $2(14)$ & \\
Diarrhea & $2(14)$ & \\
Hand-foot syndrome & $2(14)$ & \\
Hypertension & $2(14)$ & \\
Hypersensitivity & $1(7)$ \\
Hypophosphatemia & $1(7)$ \\
Pain & $2(14)$ \\
Vomiting & $1(7)$ & \\
\hline
\end{tabular}

Table 3. Correlative studies

\begin{tabular}{lccc}
\hline Biomarker & $\mathrm{n}$ & Baseline & 28 Days \\
\hline CEC $(4 \mathrm{~mL})$ & 10 & $66.1(15-347)$ & $104.4(2-254)$ \\
IL-6 $(\mathrm{pg} / \mathrm{mL})$ & 7 & $4.1(0.7-13.4)$ & $3.4(0.8-7.1)$ \\
VEGF $(\mathrm{pg} / \mathrm{mL})$ & 6 & $76.2(19.6-206.5)$ & $54.9(24.0-114.4)$ \\
sVEGF R1 $(\mathrm{pg} / \mathrm{mL})$ & 7 & $114.7(57.6-180.8)$ & $129.8(76.2-168.8)$ \\
sVEGF R2 $(\mathrm{pg} / \mathrm{mL})$ & 7 & $6152.2(4312.7-7888.4)$ & $5392.8(3446.9-6840.8)$ \\
sVEGF R3 $(\mathrm{ng} / \mathrm{mL})$ & 5 & $48.9(33.1-60.4)$ & $41.9(18.3-67.5)$ \\
Angiopoietin-2 $(\mathrm{pg} / \mathrm{mL})$ & 7 & $4717.6(2352.4-8097.7)$ & $4950.9(2401.7-9000.0)$ \\
HGF $(\mathrm{pg} / \mathrm{mL})$ & 7 & $1136.0(576.2-2109.4)$ & $897.0(416.5-1454.4)$ \\
\hline
\end{tabular}

Data are presented as mean (range)

Our study confirmed that administering post-transplant sorafenib is feasible, with an MTD of 200 mg PO BID. Exploratory biomarker data suggest that low CECs at baseline were potentially associated with a higher HCC recurrence rate. This is counterintuitive, and may be due to small sample sizes. Recurrence-free survival was promising in the trial subjects compared with our historic controls, but needs to be further explored and validated in a larger study. Only four of our patients have recurred and further follow-up is needed. Fixation artifacts may have played a role in our ability to detect p-ERK and other potentially labile phosphoproteins in explanted specimens. One factor that adversely affects phosphoprotein stability is prolonged ischemic time preceding tissue fixation. For instance, Shao and colleagues demonstrated high expression of p-AKT and p-ERK in HCC in biopsies rapidly fixed in formalin, compared to low or absent expression in corresponding resection specimens [20]. This information may help guide assessment of phosphoproteins in future studies. 


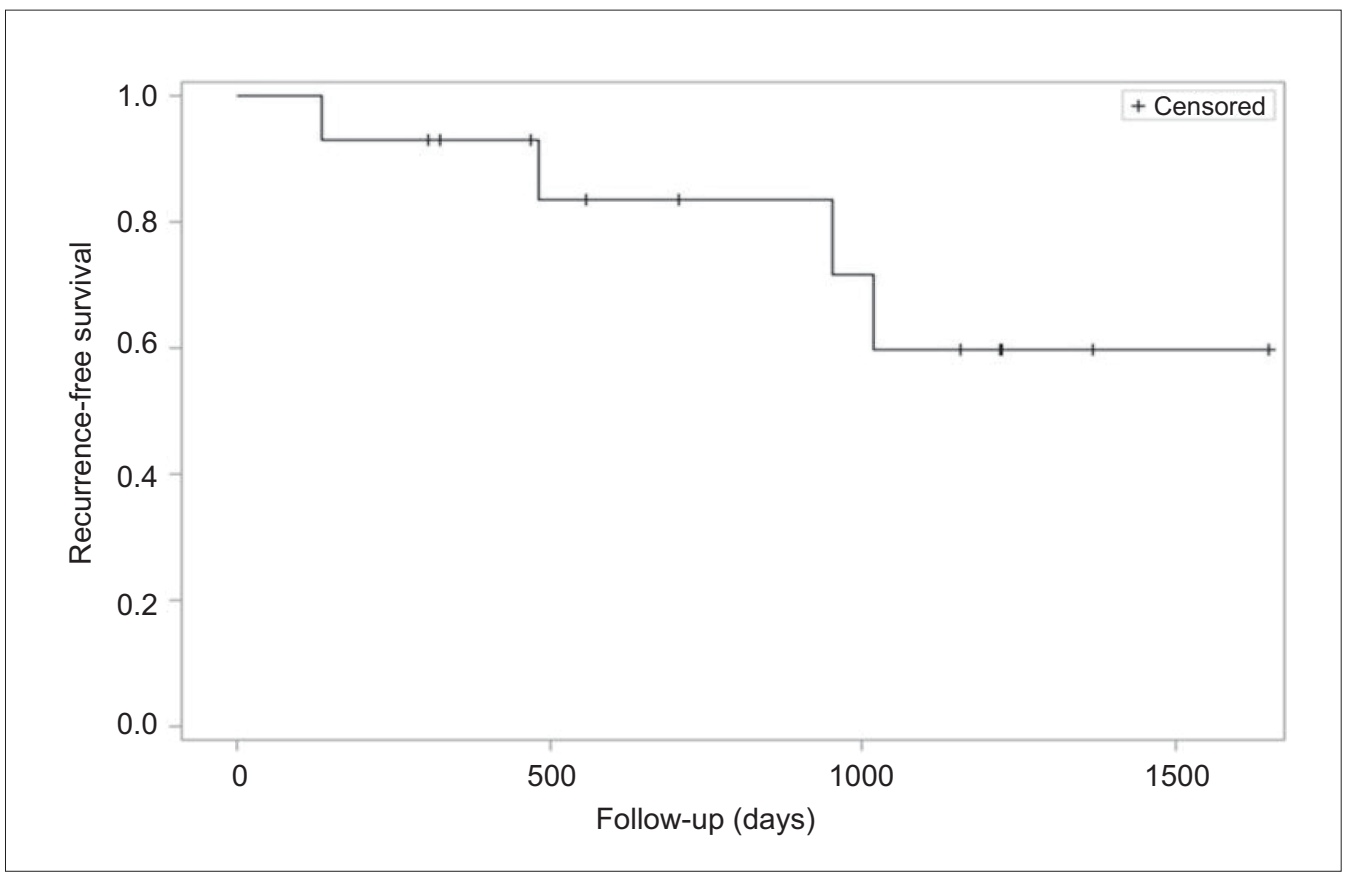

Fig. 1. Recurrence-free survival

Table 4. Patient follow-up and relative dose intensity (RDI)

\begin{tabular}{lllll}
\hline Subject No. & Initial dose level & Days on treatment & RDI & Days of follow-up \\
\hline 1 & $200 \mathrm{mg}$ QD & 168 & 1.000 & 1649 \\
2 & $200 \mathrm{mg}$ QD & 167 & 0.994 & 1613 \\
3 & $200 \mathrm{mg}$ QD & 140 & 0.762 & 1572 \\
4 & $200 \mathrm{mg}$ QD & 168 & 0.946 & 1369 \\
5 & $200 \mathrm{mg}$ QD & 170 & 1.000 & 1224 \\
6 & $200 \mathrm{mg}$ QD & 21 & 0.095 & 1222 \\
7 & $200 \mathrm{mg}$ BID & 168 & 0.893 & 1159 \\
8 & $200 \mathrm{mg}$ BID & 168 & 0.756 & 746 \\
9 & $200 \mathrm{mg}$ BID & 167 & 0.875 & 704 \\
10 & $200 / 400 \mathrm{mg}$ QD & 23 & 0.137 & 233 \\
11 & $200 / 400 \mathrm{mg}$ QD & 151 & 0.583 & 468 \\
12 & $200 / 400 \mathrm{mg}$ QD & 166 & 0.738 & 324 \\
13 & $200 / 400 \mathrm{mg}$ QD & 113 & 0.536 & 305 \\
14 & $200 / 400 \mathrm{mg}$ QD & 98 & 0.339 & 543 \\
\hline
\end{tabular}

In subset analyses, patients with advanced HCCs with underlying hepatitis C may receive a greater benefit from sorafenib [21,22]. One hypothesis for this difference is that Raf1 kinase is important for HCV replication [23, 24]. In our study, three of the four subjects who recurred had underlying HCV, although more than $70 \%$ of our population was HCV positive. Six subjects with HCV underwent liver biopsies after transplantation. Four had no fibrosis at various intervals from 5 months to 2 years after transplantation, one had grade 1 fibrosis at 
1 and 2 years, and the final patient died of rejection in the setting of multiple other medical issues. We examined these biopsies in relation to the timing of sorafenib dosing and did not see any clear signal for improvement on sorafenib, or worsening of HCV or fibrosis once treatment was stopped. We will be following up these patients over time to assess further changes; the relatively short duration of sorafenib administration and the small sample size preclude definite conclusions from being drawn at this point.

One of our patients died of rejection, with a complex post-transplant course which included an extended donor liver which was HCV positive. He had significant ascites after transplantation and required splenic artery embolization for persistent portal hypertension. While in the hospital, his immunosuppressants were changed in the setting of an infection, and it was not clear if it was this, or the sorafenib, or both, which ultimately contributed to severe rejection which led to his death.

As discussed above, preliminary results of the STORM trial assessing the potential use of sorafenib as an adjuvant treatment following definitive primary management of HCC either with surgery or ablation have become available. Tumor burden may be less after transplantation than after resection or ablation, and the pre-neoplastic remnant liver does not remain after complete removal of the liver. However, because sorafenib is primarily cytostatic in HCC, it may not be able to clear residual disease even after transplantation. Sorafenib delays recurrence after liver transplantation in animal models $[25,26]$, and it would be of interest to determine whether sorafenib delays time to recurrence in a larger trial.

The UCSF criteria have also been used to select patients for transplantation with excellent outcomes [14]. Within our cohort, six patients were also outside UCSF criteria on explant, and of those, two recurred. Finally, mTOR inhibitors are also being examined as possible treatments for HCC, and for subjects undergoing liver transplantation for cancer. Although everolimus did not demonstrate efficacy in patients with advanced HCC in a randomized trial [27], anecdotal data suggests that patients who receive mTOR inhibitors as part of an anti-rejection regimen may have a decreased risk of HCC recurrence. Large prospective trials are underway to determine if those who receive an mTOR inhibitor after transplantation for HCC have lower recurrence rates. Retrospective data and meta-analyses suggest that this may be the case [28]. It is unclear whether mTOR inhibition or sorafenib, either alone or in combination, will have a future role in post-transplant HCC patients, but our study suggests the feasibility of giving sorafenib to this patient population and defines the MTD of sorafenib for the first time in this group. A larger randomized trial recently closed due to poor accrual using the $200 \mathrm{mg}$ BID dosing schedule (NCT01624285).

\section{Disclosures}

Conflict of Interest: Dr. Finn reports consulting for Bayer/Onyx.

Financial Support: The trial was supported by Bayer/Onyx Healthcare, an NIH K23 award (CA14908401A1), and the Steven J. Levinson Medical Research Foundation (ABS).

\section{References}

1 El-Serag HB, Davila JA, Petersen NJ, McGlynn KA: The continuing increase in the incidence of hepatocellular carcinoma in the United States: an update. Ann Intern Med 2003;139:817-823.

2 Mazzaferro V, Regalia E, Doci R, Andreola S, Pulvirenti A, Bozzetti F, Montalto F, Ammatuna M, Morabito A, Gennari L: Liver transplantation for the treatment of small hepatocellular carcinomas in patients with cirrhosis. N Engl J Med 1996;334:693-699. 
3 Siegel AB, McBride RB, El-Serag HB, Hershman DL, Brown RS Jr, Renz JF, Emond J, Neugut AI: Racial disparities in utilization of liver transplantation for hepatocellular carcinoma in the United States, 19982002. Am J Gastroenterol 2008;103:120-127.

4 Roayaie S, Schwartz JD, Sung MW, Emre SH, Miller CM, Gondolesi GE, Krieger NR, Schwartz ME: Recurrence of hepatocellular carcinoma after liver transplant: patterns and prognosis. Liver Transpl 2004;10:534540.

5 Wilhelm SM, Carter C, Tang L, Wilkie D, McNabola A, Rong H, Chen C, Zhang X, Vincent P, McHugh M, Cao Y, Shujath J, Gawlak S, Eveleigh D, Rowley B, Liu L, Adnane L, Lynch M, Auclair D, Taylor I, Gedrich R, Voznesensky A, Riedl B, Post LE, Bollag G, Trail PA: BAY 43-9006 exhibits broad spectrum oral antitumor activity and targets the RAF/MEK/ERK pathway and receptor tyrosine kinases involved in tumor progression and angiogenesis. Cancer Res 2004;64:7099-7109.

6 Nonomura A, Ohta G, Hayashi M, Izumi R, Watanabe K, Takayanagi N, Mizukami Y, Matsubara F: Immunohistochemical detection of ras oncogene p21 product in liver cirrhosis and hepatocellular carcinoma. Am J Gastroenterol 1987;82:512-518.

7 Park YN, Kim YB, Yang KM, Park C: Increased expression of vascular endothelial grow th factor and angiogenesis in the early stage of multistep hepatocarcinogenesis. Arch Pathol Lab Med 2000;124:1061-1065.

8 Llovet JM, Ricci S, Mazzaferro V, Hilgard P, Gane E, Blanc JF, de Oliveira AC, Santoro A, Raoul JL, Forner A, Schwartz M, Porta C, Zeuzem S, Bolondi L, Greten TF, Galle PR, Seitz JF, Borbath I, Häussinger D, Giannaris T, Shan M, Moscovici M, Voliotis D, Bruix J, SHARP Investigators Study Group: Sorafenib in advanced hepatocellular carcinoma. N Engl J Med 2008;359:378-390.

9 Cheng AL, Kang YK, Chen Z, Tsao CJ, Qin S, Kim JS, Luo R, Feng J, Ye S, Yang TS, Xu J, Sun Y, Liang H, Liu J, Wang J, Tak WY, Pan H, Burock K, Zou J, Voliotis D, Guan Z: Efficacy and safety of sorafenib in patients in the Asia-Pacific region with advanced hepatocellular carcinoma: a phase III randomised, double-blind, placebo-controlled trial. Lancet Oncol 2009;10:25-34.

10 Bruix J, Takayama T, al MVe: STORM: A phase III randomized, double-blind, placebo-controlled trial of adjuvant sorafenib after resection or ablation to prevent recurrence of hepatocellular carcinoma (HCC), ASCO, 2014.

11 Gruenwald V, Beutel G, Schuch-Jantsch S, Reuter C, Ivanyi P, Ganser A, Haubitz M: Circulating endothelial cells are an early predictor in renal cell carcinoma for tumor response to sunitinib. BMC Cancer 2010;10:695-703.

12 Miyahara K, Nouso K, Morimoto Y, Takeuchi Y, Hagihara H, Kuwaki K, Onishi H, Ikeda F, Miyake Y, Nakamura S, Shiraha H, Takaki A, Honda M, Kaneko S, Sato T, Sato S, Obi S, Iwadou S, Kobayashi Y, Takaguchi K, Kariyama K, Takuma Y, Takabatake H, Yamamoto K, Okayama Liver Cancer Group: Pro-angiogenic cytokines for prediction of outcomes in patients with advanced hepatocellular carcinoma. Br J Cancer 2013;109:2072-2078.

13 Llovet JM, Peña CE, Lathia CD, Shan M, Meinhardt G, Bruix J, SHARP Investigators Study Group: Plasma biomarkers as predictors of outcome in patients with advanced hepatocellular carcinoma. Clin Cancer Res 2012;18:2290-2300.

14 Yao FY, Ferrell L, Bass NM, Watson JJ, Bacchetti P, Venook A, Ascher NL, Roberts JP: Liver transplantation for hepatocellular carcinoma: expansion of the tumor size limits does not adversely impact survival. Hepatology 2001;33:1394-1403.

15 Strumberg D, Clark JW, Awada A, Moore MJ, Richly H, Hendlisz A, Hirte HW, Eder JP, Lenz HJ, Schwartz B: Safety, pharmacokinetics, and preliminary antitumor activity of sorafenib: a review of four phase I trials in patients with advanced refractory solid tumors. Oncologist 2007;12:426-437.

16 Santoro A, Rimassa L, Borbath I, Daniele B, Salvagni S, Van Laethem JL, Van Vlierberghe H, Trojan J, Kolligs FT, Weiss A, Miles S, Gasbarrini A, Lencioni M, Cicalese L, Sherman M, Gridelli C, Buggisch P, Gerken G, Schmid RM, Boni C, Personeni N, Hassoun Z, Abbadessa G, Schwartz B, Von Roemeling R, Lamar ME, Chen Y, Porta C: Tivantinib for second-line treatment of advanced hepatocellular carcinoma: a randomised, placebo-controlled phase 2 study. Lancet Oncol 2013;14:55-63.

17 Saab S, McTigue M, Finn RS, Busuttil RW: Sorafenib as adjuvant therapy for high-risk hepatocellular carcinoma in liver transplant recipients: feasibility and efficacy. Exp Clin Transplant 2010;8:307-313.

18 Jia N, Liou I, Halldorson J, Carithers R, Perkins J, Reyes J, Yeh M, Stohr E, Rao S, Lin EH: Phase I adjuvant trial of sorafenib in patients with hepatocellular carcinoma after orthotopic liver transplantation. Anticancer Res 2013;33:2797-2800.

19 Yoon DH, Ryoo BY, Ryu MH, Lee SG, Hwang S, Suh DJ, Lee HC, Kim TW, Ahn CS, Kim KH, Moon DB, Kang YK: Sorafenib for recurrent hepatocellular carcinoma after liver transplantation. Jpn J Clin Oncol 2010;40:768-773.

20 Shao YY, Chen CL, Ho MC, Huang CC, Tu HC, Hsu CH, Cheng AL: Dissimilar immunohistochemical expression of ERK and AKT between paired biopsy and hepatectomy tissues of hepatocellular carcinoma. Anticancer Res 2012;32:4865-4870.

21 Bruix J, Raoul JL, Sherman M, Mazzaferro V, Bolondi L, Craxi A, Galle PR, Santoro A, Beaugrand M, Sangiovanni A, Porta C, Gerken G, Marrero JA, Nadel A, Shan M, Moscovici M, Voliotis D, Llovet JM: Efficacy and safety of sorafenib in patients with advanced hepatocellular carcinoma: subanalyses of a phase III trial. J Hepatol 2012;57:821-829.

22 Cheng AL, Kang YK, Lin DY, Park JW, Kudo M, Qin S, Chung HC, Song X, Xu J, Poggi G, Omata M, Pitman Lowenthal S, Lanzalone S, Yang L, Lechuga MJ, Raymond E: Sunitinib versus sorafenib in advanced hepatocellular cancer: results of a randomized phase III trial. J Clin Oncol 2013;31:4067-4075. 
23 Aoki H, Hayashi J, Moriyama M, Arakawa Y, Hino O: Hepatitis C virus core protein interacts with 14-3-3 protein and activates the kinase Raf-1. J Virol 2000;74:1736-1741.

24 Himmelsbach K, Sauter D, Baumert TF, Ludwig L, Blum HE, Hildt E: New aspects of an anti-tumour drug: sorafenib efficiently inhibits HCV replication. Gut 2009;58:1644-1653.

25 Takahara T, Nitta H, Hasegawa Y, Itou N, Takahashi M, Wakabayashi G: Using sorafenib for recurrent hepatocellular carcinoma after liver transplantation-interactions between calcineurin inhibitor: two case reports. Transplant Proc 2011;43:2800-2805.

26 Yan J, Tan C, Gu F, Jiang J, Xu M, Huang X, Dai Z, Wang Z, Fan J, Zhou J: Sorafenib delays recurrence and metastasis after liver transplantation in a rat model of hepatocellular carcinoma with high expression of phosphorylated extracellular signal-regulated kinase. Liver Transpl 2013;19:507-520.

27 Zhu A, Kudo M, Assinat E, et al: EVOLVE-1: Phase 3 Study of everolimus for advanced HCC that progressed during or after sorafenib, GI ASCO. San Francisco, CA, 172, 2014

28 Liang W, Wang D, Ling X, Kao AA, Kong Y, Shang Y, Guo Z, He X: Sirolimus-based immunosuppression in liver transplantation for hepatocellular carcinoma: a meta-analysis. Liver Transpl 2012;18:62-69. 